\title{
Determinants of Utilization
}

\section{The Complementarity and Substitution between Unconventional and Mainstream Medicine among Racial and Ethnic Groups in the United States}

\author{
K. Tom Xu and Tommie W. Farrell
}

Objectives. To describe racial and ethnic differences in the utilization patterns of 12 common types of complementary and alternative medicine (CAM) and mainstream medicine (MSM) and to test whether a specific CAM type is a substitute for or a complement to MSM among five racial and ethnic groups in the United States.

Methods. The Medical Expenditure Panel Survey in 1996 and 1998 were used. The sample of 46,673 respondents was stratified into non-Hispanic whites (NHW), Hispanics, blacks, Asians, and other races. Twelve types of CAM visits and visits to office-based and outpatient physicians were used to describe the pattern of CAM and MSM use. Utilization patterns among each racial and ethnic group were established and compared. Multivariate analyses were conducted to test whether each type of CAM and MSM were complements or substitutes within a racial and ethnic group, controlling for respondents' sociodemographics and health.

Results. Significant intergroup differences in the prevalence rates of using various types of CAM were found. In particular, for some racial and ethnic groups, CAM can be either a substitute for or a complement to MSM visits, depending on the CAM type. More complementary relationships between CAM and physician visits were found in NHW and Asians than in other groups. All significant relationships between CAM types and physician visits among Hispanics and other races (predominantly Native American Indians) were substitution.

Conclusions. Complementarity and substitution of CAM and MSM varied by racial and ethnic groups and by type of CAM. Culturally sensitive approaches are needed in successful integration of CAM in treatment management.

Racial and ethnic differences have been extensively studied in modern medical research in the United States as equality in health has become one of the priority issues of health policies. To some extent, racial and ethnic differences are a more important issue in the research of complementary and alternative medicine (CAM) than in mainstream medicine (MSM), because some forms 
of CAM originated from the native countries or regions of the ethnic and racial minority groups in the United States. For example, acupuncture was introduced by the Chinese culture and herbal medication use is prevalent among native Asians, Mexicans, and American Indians. One study found that 44 percent of a Mexican-American sample used herbal medicine and about 30 percent used spiritual healing (Keegan 1996). As compared with non-Hispanic white (NHW) primary care patients, Hispanics were found to be more likely to use folk remedies (Palinkas and Kabongo 2000). Also, one study showed that African American women used CAM for a wide range of health conditions and prevention (Cushman et al. 1999). Another study of Chinese immigrants showed that 95 percent of the sample used self-treatment and home remedies (Ma 1999). In a sample of Navajo Indians, 62 percent used native healers and 39 percent used healers on a regular basis (Kim and Kwok 1998).

Despite the possibility that minority groups may be more predisposed to CAM use through their respective and distinctive cultures than NHW in the United States, several studies have demonstrated that NHW in the United States were more likely to be CAM users than the members of the minority groups (Bausell, Lee, and Berman 2001; Bair et al. 2002; Baldwin et al. 2002; $\mathrm{Ni}$, Simile, and Hardy 2002; Shumay et al. 2002). Other studies showed no significant racial or ethnic differences in the prevalence of CAM use (Elder, Gillcrist, and Minz 1997; Liu et al. 2000; Cherniack, Senzel, and Pan 2001; Mackenzie et al. 2003; McCurdy et al. 2003). One possible explanation for these conflicting findings may be that the content of CAM defined in the studies differed. For example, Asians were higher users of acupuncture and oriental medicine and Hispanics were higher users of dietary supplements and home remedies, whereas NHW were higher users of chiropractic massage and vitamins (Najm et al. 2003).

Although some researchers suggested that CAM was a substitute for MSM in the United States (Gundling 1998), more studies demonstrated that the unconventional treatments were complementary to the MSM (Eisenberg et al. 1993, 1998; Spigelblatt et al. 1994; Paramore 1997; Astin 1998). Using a nationally representative sample, one study examined the association between the utilization of CAM and MSM, and found that CAM was more of an "add on" to MSM than a substitute (Druss and Rosenheck 1999). It is still unknown,

Address correspondence to K. Tom Xu, Ph.D., Department of Family and Community Medicine, School of Medicine, MS 8161, Texas Tech University Health Sciences Center, Lubbock, TX 79430.Tommie W. Farrell, M.D., is with the Department of Family and Community Medicine, School of Medicine, Texas Tech University Health Sciences Center, Lubbock, TX. 
however, whether the complementarity of CAM to MSM is characteristic of only the majority culture or racial group in the United States and how the utilization of and association between CAM and MSM differ by racial and ethnic minority groups.

One of the major challenges in studying CAM use among minority groups is to get a sample that is large enough to produce nationally representative estimates for each minority group and to make the estimates from these subpopulations comparable. Following the conceptualization of a previous study (Druss and Rosenheck 1999), the current study utilized a sample of 46,673 subjects representing the U.S. population to:

(1) describe racial and ethnic differences in the utilization patterns of 12 common CAM types and MSM; and

(2) test whether a specific type of CAM is a substitute for or a complement to MSM among five racial and ethnic groups in the United States.

\section{METHODS}

\section{The Sample}

The Medical Expenditure Panel Survey (MEPS) conducted by the Agency for Healthcare Research and Quality was used in the study. The sampling frame for the household survey component was drawn from respondents in the National Health Interview Survey. Hispanics and blacks were oversampled. More details on the data collection process, survey design, and methodology can be found elsewhere (Cohen 1997). To provide meaningful and nationally representative estimates for minority groups that usually have small sample size of CAM users in surveys, public data from 1996 and 1998 were pooled using each year's Full Year Consolidated Data File (AHRQ). There were no overlapping panels in these 2 years. To construct a single nationally representative cross-sectional sample, person level weights were recalculated and the strata reassigned.

In the sample of 46,673 subjects, 22,601 were from 1996 and 24,072 from 1998. The racial/ethnic groups were defined as NHW (71.91 percent), Hispanics (10.07 percent), blacks or African Americans (13.12 percent), Asians (3.85 percent), and other races (1.05 percent). The other races category included Eskimos, Aleuts, Native American Indians, and others. Over 90 percent of the other races were Native American Indians. The racial and 
ethnic proportions derived from the pooled sample were very similar $(<1$ percent difference for each group) to those published by the Census Bureau for the period of 1996-1998 (U.S. Census Bureau).

\section{CAM and MSM Utilization}

The detailed description of the CAM visit questions used in the MEPS can be found in several studies and on the MEPS website (AHRQ; Druss and Rosenheck 1999; Bausell, Lee, and Berman 2001; Egede et al. 2002; Davis and Darden 2003). Subjects in the MEPS were asked, "In order to get as complete a picture as possible of all sources of health care, we would also like to ask about the use of other forms of health care, including treatment you many have previously told me about, such as the treatments shown on this card. Frequently this type of care is referred to as complementary or alternative care. During the calendar year 1996, for health reasons, did you consult someone who provides theses types of treatments?" The types of CAM included in the MEPS were: chiropractics, massage therapy, herbal remedies, spiritual healings or prayers, nutritional advice, acupuncture, meditation/imagery/relaxation, homeopathy, traditional medicine, biofeedback training, hypnosis, and others. Based on these data, one binary variable indicating whether a subject had any CAM visits and a set of dummy variables indicating the use of each type of CAM were created.

The counterparts of the CAM visit variables were MSM physician visits. Specifically, to make CAM and MSM visits comparable, office-based and outpatient physician visits were used. Two variables were created for MSM utilization: a binary variable indicating whether a subject had any physician visits in a year and a count variable of how many physician visits a subject had among those who had at least one physician visit.

\section{Sociodemographic and Health Variables}

The sociodemographic characteristics of the subjects included in the study were age, sex, education ( $\geq$ high school or not), poverty class (mid-high income versus low income and poor), health insurance status (with or without insurance), and region (Northeast, Midwest, South, and West). The choice of these control variables was based on several previous studies using the MEPS data studying CAM use (Druss and Rosenheck 1999; Bausell, Lee, and Berman 2001; Egede et al. 2002; Davis and Darden 2003). These variables can be categorized as predisposing, enabling and need factors that are components of 
the theoretical behavioral model to predict utilization (Andersen and Newman 1973).

Two health measures were used as additional control variables. The first one described a subject's general physical and mental health status and the second one indicated specific conditions. In the MEPS, subjects were asked to rate their overall physical and mental health as "excellent," "very good," "good," "fair," or "poor." Although some researchers used dichotomization (fair/poor versus good/very good/excellent) for the categorical self-rated health (Kennedy et al. 1998; Soobader and LeClere 1999; Kahn et al. 2000; Subramania, Kawachi, and Kennedy 2001), others argued that this dichotomization would lose information in the data and that the assignment of the cutoff point was arbitrary (Wagstaff and Van Doorslaer 1994; Kakwani et al. 1997; Gerdtham et al. 1999; Humphries and van Doorslaer 2000). The alternative approach was to use a latent continuous ill health variable that generated the categorical variable of self-reported health. Because self-reported health was skewed, a log-normal distribution of the latent health was usually employed (Kunst, Geurts, and van den Berg 1995; van Doorslaer et al. 1997). The categorical self-rated health of the entire U.S. population was mapped onto a log-normal distribution. The numerical counterparts of the categories for physical health were 0.349 (excellent), 1.025 (very good), 2.214 (good), 4.586 (fair), and 9.854 (poor); for mental health, 0.417, 1.300, 2.889, 6.480 , and 13.368 , respectively.

To control for the possibility that patients with chronic and/or severe conditions were more likely to have MSM and CAM visits regardless of their self-reported overall health, nine conditions were included: cancer (of any body parts), diabetes, emphysema, high cholesterol, hypertension, arthritis, asthma, back problems of any kind, and depression and anxiety disorders. These conditions were selected from the MEPS priority condition list in which prevalent, chronic, severe and costly conditions were included. The priority conditions that had $<1$ percent prevalence in the data (e.g., stomach ulcers and HIV/AIDS) were combined into one variable called "other priority conditions." Lastly, an additional dummy variable was created to indicate whether a subject had any other conditions or diseases that were not in the priority condition list.

\section{Statistical Analyses}

Descriptive analyses were performed on the respondents' overall utilization of CAM and MSM visits to address the first objective. The first set of variables 
analyzed was the probability of having at least one CAM visit and the utilization of CAM and MSM. The variable of CAM/MSM utilization categorized the subjects into four groups: users of both CAM and MSM, users of only MSM, users of only CAM, and nonuser of either CAM or MSM. Utilization of specific CAM types was also analyzed among the five racial/ethnic groups. Nationally representative estimates for each racial/ethnic group were obtained.

To address the second objective, i.e., to test whether a specific CAM type is a substitute for or a complement to MSM among each racial and ethnic group, multivariate analyses were performed. A two-part model that is commonly used to model health services utilization data was adopted (Watts, Scheffler, and Jewell 1986; Mullahy 1998; Lillard, Rogowski, and Kington 1999). The first part modeled the probability of using MSM with CAM use as independent variables, controlling for sociodemographic characteristics, overall health and specific conditions of the respondents, as shown in Table 1. A logistic model specification was used. The second part modeled the number of MSM visits among respondents who had at least one MSM visit. Because the distribution of MSM visits was skewed and the approximation of a normal distribution through a log transformation was poor, a negative binomial regression was used. Negative binomial regressions are commonly used for the number of visits that are considered as count data with overdispersion (Kilpatrick 1977; Joyce et al. 2000; Schellhorn et al. 2000; Sharma et al. 2000; Hakkinen 2002; Burge, Lawson, and Johnston 2003). The complex sampling design of the MEPS was incorporated in all analyses using STATA 8.0 (STATA Corporation $^{\mathbb{B}}$ ) to produce nationally representative estimates.

Because both equations in the two-part model were nonlinear, marginal effects were used to describe the relationship between CAM and MSM visits based on the parameter estimates from the estimations. Marginal effects indicate how much MSM use would change given a change in CAM use. Marginal effects used in this study were evaluated at the means of the variables. The unconditional marginal effects of CAM use on the expected number of MSM visits, i.e., the number of MSM visits adjusted by the probability of having any MSM visits, based on the estimates from the logistic and the negative binomial equations were obtained (Farrell, Manning, and Finch 2003).

\section{RESULTS}

Between 1996 and 1998, the proportion of NHW who used CAM was 5.12 percent. The proportions for Hispanics, blacks, Asians, and other races were 
$2.68,2.01,4.07$, and 6.28 percent, respectively. Table 1 reports the sociodemographic and health characteristics for each racial/ethnic group. The proportion of MSM users across the racial and ethnic groups ranged from 55.08 percent (Hispanic) to 72.52 percent (NHW). The average numbers of MSM visits ranged from 3.84 (Asian) to 5.27 (NHW) among users. Table 2 indicates

Table 1: Descriptive Statistics of the Sample $(n=46,673)^{*}$

\begin{tabular}{|c|c|c|c|c|c|}
\hline & $\begin{array}{c}N H W \\
(n=27,584)\end{array}$ & $\begin{array}{c}\text { Hispanic } \\
(n=9,601)\end{array}$ & $\begin{array}{c}\text { Black } \\
(n=7,196)\end{array}$ & $\begin{array}{c}\text { Asian } \\
(n=1,622)\end{array}$ & $\begin{array}{c}\text { Other } \\
(n=670)\end{array}$ \\
\hline$\%$ of MSM users & 72.52 & 55.08 & 58.01 & 56.46 & 60.77 \\
\hline $\begin{array}{l}\text { \# of MSM visits (among MSM } \\
\text { users) }\end{array}$ & $\begin{array}{r}5.27 \\
(0.06)\end{array}$ & $\begin{array}{c}4.55 \\
(0.16)\end{array}$ & $\begin{array}{c}4.25 \\
(0.12)\end{array}$ & $\begin{array}{c}3.84 \\
(0.19)\end{array}$ & $\begin{array}{l}4.55 \\
(0.41)\end{array}$ \\
\hline Age & $\begin{array}{l}37.23 \\
(0.25)\end{array}$ & $\begin{array}{c}27.81 \\
(0.33)\end{array}$ & $\begin{array}{c}30.52 \\
(0.39)\end{array}$ & $\begin{array}{l}31.75 \\
(0.67)\end{array}$ & $\begin{array}{c}27.74 \\
(1.09)\end{array}$ \\
\hline Female $(\%)$ & 51.09 & 49.16 & 53.17 & 49.62 & 52.22 \\
\hline Education $\geq$ high school (\%) & 62.43 & 34.15 & 46.78 & 58.20 & 42.18 \\
\hline Have insurance $(\%)$ & 90.16 & 72.20 & 84.23 & 84.16 & 80.16 \\
\hline Mid-high income (\%) & 75.20 & 41.96 & 46.63 & 72.04 & 49.66 \\
\hline Northeast (\%) & 20.30 & 14.74 & 18.72 & 16.16 & 6.29 \\
\hline Midwest (\%) & 27.49 & 7.19 & 18.03 & 7.48 & 16.48 \\
\hline South $(\%)$ & 32.60 & 33.04 & 54.46 & 17.82 & 31.55 \\
\hline West $(\%)$ & 19.61 & 45.03 & 8.79 & 58.54 & 45.68 \\
\hline Overall physical health & $\begin{array}{c}1.54 \\
(0.16)\end{array}$ & $\begin{array}{c}1.71 \\
(0.04)\end{array}$ & $\begin{array}{c}1.73 \\
(0.04)\end{array}$ & $\begin{array}{c}1.50 \\
(0.06)\end{array}$ & $\begin{array}{c}1.78 \\
(0.10)\end{array}$ \\
\hline Overall mental health & $\begin{array}{c}1.54 \\
(0.02)\end{array}$ & $\begin{array}{l}1.69 \\
(0.04)\end{array}$ & $\begin{array}{c}1.72 \\
(0.05)\end{array}$ & $\begin{array}{l}1.48 \\
(0.07)\end{array}$ & $\begin{array}{l}1.75 \\
(0.11)\end{array}$ \\
\hline \multicolumn{6}{|l|}{ Specific conditions } \\
\hline Cancer (of any body parts) (\%) & 4.70 & 1.40 & 1.76 & 1.56 & 2.26 \\
\hline Diabetes $(\%)$ & 3.83 & 4.03 & 4.61 & 2.51 & 4.96 \\
\hline Emphysema $(\%)$ & 6.10 & 2.91 & 2.84 & 1.91 & 6.49 \\
\hline High cholesterol (\%) & 4.34 & 1.63 & 1.68 & 2.62 & 2.60 \\
\hline Hypertension $(\%)$ & 11.27 & 5.87 & 12.68 & 7.67 & 7.33 \\
\hline Arthritis $(\%)$ & 6.58 & 3.47 & 5.20 & 3.01 & 4.89 \\
\hline Asthma (\%) & 3.83 & 3.86 & 5.59 & 2.46 & 6.77 \\
\hline Back problems of any kind (\%) & 9.36 & 6.04 & 5.52 & 7.42 & 7.16 \\
\hline $\begin{array}{l}\text { Depression and anxiety disorders } \\
(\%)\end{array}$ & 9.82 & 5.84 & 6.03 & 4.30 & 5.88 \\
\hline Other priority conditions ${ }^{\dagger}$ & 5.82 & 2.73 & 3.87 & 2.07 & 4.32 \\
\hline Other conditions $(\%)$ & 48.46 & 49.37 & 44.75 & 50.71 & 51.90 \\
\hline
\end{tabular}

*Nationally representative estimates are shown. Numbers in parentheses are standard errors for continuous variables.

${ }^{\dagger}$ Other priority conditions include HIV/AIDS, ischemic heart disease, stroke, gall bladder disease, stomach ulcer, Alzheimer's disease, and other dementias, each of which had a prevalence rate less than $1 \%$ in the data.

MSM, mainstream medicine; NHW, non-Hispanic whites. 
Table 2: Selected CAM Use by Conditions

\begin{tabular}{|c|c|c|c|}
\hline Condition & CAM 1 & CAM 2 & CAM 3 \\
\hline Cancer (of any body parts) & Massage $(31 \%)$ & Herbs $(31 \%)$ & Nutritional $(25 \%)$ \\
\hline Diabetes & Nutritional (37\%) & Herbs $(28 \%)$ & Spiritual $(26 \%)$ \\
\hline Emphysema & Massage $(36 \%)$ & Herbs $(36 \%)$ & Spiritual (25\%) \\
\hline High cholesterol & Nutritional (33\%) & Herbs $(32 \%)$ & Massage (28\%) \\
\hline Hypertension & Spiritual $(31 \%)$ & Herbs $(31 \%)$ & Nutritional $(26 \%)$ \\
\hline Arthritis & Herbs $(38 \%)$ & Massage $(29 \%)$ & Nutritional $(28 \%)$ \\
\hline Asthma & Herbs $(35 \%)$ & Spiritual $(27 \%)$ & Massage $(26 \%)$ \\
\hline Back problems of any kind & Massage $(45 \%)$ & Herbs $(28 \%)$ & Chiropractic $(24 \%)$ \\
\hline Depression and anxiety disorders & Herbs $(38 \%)$ & Massage (37\%) & Spiritual $(30 \%)$ \\
\hline
\end{tabular}

CAM, complementary and alternative medicine.

the three most prevalent CAM types used among CAM users with selected diseases/conditions.

Table 3 presents the results describing the utilization pattern of CAM and MSM visits. About 1.48 percent (Hispanic) to 5.59 percent (Other) used

Table 3: CAM and MSM Utilization*

\begin{tabular}{|c|c|c|c|c|c|}
\hline & $N H W$ & Hispanic & Black & Asian & Other \\
\hline \multicolumn{6}{|l|}{ Overall utilization pattern } \\
\hline Having CAM visits (\%) & 5.12 & 2.68 & 2.01 & 4.07 & 6.28 \\
\hline Both MSM and CAM & 4.22 & 2.11 & 1.48 & 2.85 & 5.59 \\
\hline MSM only & 68.31 & 52.97 & 56.53 & 53.61 & 55.18 \\
\hline CAM only & 0.90 & 0.57 & 0.53 & 1.23 & 0.69 \\
\hline Neither & 26.58 & 44.35 & 41.46 & 42.32 & 38.54 \\
\hline \multicolumn{6}{|l|}{ Types CAM (among users) } \\
\hline Massage & 36.59 & 26.67 & 20.65 & 25.38 & 42.26 \\
\hline Herbal & 34.35 & 33.31 & 18.83 & 34.68 & 18.67 \\
\hline Spiritual & 25.44 & 27.17 & 48.86 & 18.51 & 20.75 \\
\hline Nutritional & 20.98 & 15.08 & 26.27 & 13.64 & 11.20 \\
\hline Chiropractic & 14.47 & 9.46 & 6.07 & 3.77 & 8.74 \\
\hline Homeopathy & 12.96 & 13.47 & 5.02 & 3.60 & 13.94 \\
\hline Acupuncture & 9.36 & 14.03 & 6.94 & 18.44 & 0 \\
\hline Meditation & 8.91 & 7.12 & 8.02 & 11.45 & 8.97 \\
\hline Traditional & 4.22 & 3.00 & 1.43 & 26.06 & 33.69 \\
\hline Biofeedback & 1.92 & 0 & 2.01 & 0 & 0 \\
\hline Hypnosis & 1.23 & 0 & 2.68 & 0 & 0 \\
\hline Other & 33.12 & 30.52 & 25.14 & 35.65 & 44.66 \\
\hline
\end{tabular}

*Nationally representative estimates are shown.

CAM, complementary and alternative medicine; MSM, mainstream medicine. 
Table 4: Marginal Effects of CAM Visits on the Number of MSM visits*

\begin{tabular}{lccccr}
\hline & NHW & Hispanic & Black & Asian & Other \\
\hline Any CAM visits & 0.458 & & & -2.371 & 0.942 \\
Chiropractic & 0.543 & & & & -3.656 \\
Acupuncture & 1.539 & & 0.796 & & \\
Nutritional & 1.015 & & 0.805 & 0.952 & \\
Massage & & & 0.984 & -3.230 \\
Herbal & & & & -1.409 \\
Biofeedback & & & & -2.876 & \\
Meditation & & -1.276 & & 0.855 & \\
Homeopathy & -0.649 & -0.848 & & & \\
Spiritual & & & -1.163 & 0.958 & \\
Hypnosis & & & -1.271 & \\
Traditional & -0.776 & & & & \\
Other & & & & \\
\end{tabular}

*Unconditional marginal effects (ME) obtained from the two-part multivariate model. Unconditional $\mathrm{ME}=\mathrm{ME}$ (logistic) $\times N+\mathrm{ME}$ (negative binomial) $\times$ Prob $(N>0)$. ME (logistic) and ME (negative binomial) are the marginal effects of CAM use in the logistic and negative binomial equations, respectively. $N$ is the mean number of MSM visits among MSM users and Prob $(N>0)$ is the probability of having any MSM visits. Statistically significant $(p<.05)$ results are shown. The control variables used are shown in Table 1.

CAM, complementary and alternative medicine; MSM, mainstream medicine; NHW, non-Hispanic whites.

both MSM and CAM. Over half of the population used only MSM. The proportion ranged from 52.97 percent (Hispanic) to 68.31 percent (NHW). Approximately 1.23 percent of Asians used only CAM whereas only 0.57 percent of Hispanics used only CAM. The second part of Table 3 shows the use of various types of CAM within each racial/ethnic group. Among NHWs and other races, the most frequently used CAM was massage (36.56 percent for NHW and 42.26 percent for other races). For Hispanics and Asians, the most frequently used CAM was herbal remedies, 33.31 and 34.68 percent, respectively. Among blacks, 48.86 percent used spiritual healings or prayers. It should be noted, however, that a substantial proportion of each racial/ethnic group, particularly other races, the vast majority of whom being Native American Indians, used "other" types of CAM.

Table 4 reports the multivariate analysis results. The unconditional marginal effects of CAM use on the expected number of MSM visits are shown. Estimates that were not statistically significant at $\alpha=0.05$ were considered as having zero influence in calculating the unconditional marginal effects. 


\section{$N H W$}

The first CAM visit was a complement to MSM visits, indicated by the significant and positive marginal effect of the variable "any CAM visits." Among CAM users, chiropractic, acupuncture, and nutritional advice were complements to MSM visits. In contrast, spiritual healing or prayer and other CAM were substitutes for MSM visits, indicated by the significant and negative marginal effects of these two variables. The use of massage, herbal remedies, meditation, biofeedback, homeopathy, hypnosis, and traditional remedies were independent of MSM visits among CAM users.

\section{Hispanics}

The first CAM visit was found to be independent of MSM visits among Hispanics. Two statistically significant relationships between CAM types and MSM visits indicated substitution. These CAM types were homeopathy and spiritual healings.

\section{African Americans}

Similar to that among Hispanics, the first CAM visit was independent of MSM visits among this racial group. Among CAM users, acupuncture and massage were found to be complements to MSM visits whereas biofeedback and traditional medicine were substitutes.

\section{Asians}

The first CAM visit was found to be a substitute for MSM visits among Asians. In particular, homeopathy and other CAM types were substitutes for MSM visits. However, massage, herbal medicine, traditional medicine, and spiritual healing were found to be complements to MSM visits. The use of the other six types of CAM was independent of MSM visits.

\section{Other Races}

Over 90 percent of the other races were Native American Indians. Among this group, the first CAM visit was positively associated with MSM visits, as observed among NHW. All statistically significant relationships between CAM types and MSM visits indicated substitution: chiropractics, herbal remedies, and meditation. The substitutions of herbal remedies and chiropractics for MSM in this group were the strongest among all significant relationships found in this study. The other CAM types were independent of MSM visits. 


\section{DISCUSSION}

A previous study suggested that CAM visits served more as complements or add-on's than substitutes to MSM visits in the general population of United States (Druss and Rosenheck 1999). The findings from the current study demonstrated that there were substantial variations in the utilization patterns of MSM and CAM across different racial and ethnic subpopulations. Significant intergroup differences in the prevalence rates of using various types of CAM were also found.

The second objective of the current study was to address whether MSM and CAM visits were substitutes or complements among different racial and ethnic groups. Although the use of many types of CAM was independent of MSM use, complementarity between CAM and MSM was found in three types of CAM among NHW and four among Asians. All significant relationships between CAM types and MSM among Hispanics and other races (predominantly Native American Indians) were substitution. The effect of substitution was the strongest among other races.

In addition to demonstrating that both substitutive and complementary relationships were in place when the U.S. population was stratified by racial and ethnic groups, the current study investigated the CAM use pattern within each racial/ethnic group using a single nationally representative sample. In contrast, many previous studies of CAM use among minority groups focused on a single racial/ethnic group (Keegan 1996; Kim and Kwok 1998; Cushman et al. 1999; Ma 1999). Because of different study designs, lack of representation of the population and small sample sizes, direct comparisons between the results of these studies to establish racial and ethnic differences could not be substantiated. Despite the differences between the current study and previous studies on minority groups, the current study's findings of minority groups' utilization of CAM were in line with those from previous studies (e.g., the high prevalence of herbal remedy use among Asians and Hispanics).

It is important to recognize that there is not a universal pattern of CAM use across subgroups of patients. The current study indicates that for each $\mathrm{racial} / \mathrm{ethnic}$ group, there are one or two predominant CAM types and the prevalent types differ by race and ethnicity. In addition, patients' CAM utilization patterns differ by the diseases and conditions they have. For the prevalent and chronic conditions, it seems that herbal medicine, nutritional advice, and spiritual healings are the most commonly used.

Open communications about CAM use by the patient with the physician can foster more collaboration, strengthen the patient-physician relationship 
and allow monitoring of potential adverse side-effects or drug interactions. As more of CAM is integrated into the regular practice of medicine, it would seem that the trend toward CAM treatments as complements rather than substitutes would increase. However this is less likely to occur in certain types of CAM, as suggested by the findings from the current study. For example, it would be difficult for the physicians or other health care workers to play the role of provider in spiritual healings. In these instances, the recognition and acceptance of health benefits from CAM by physicians is needed to keep a welcome environment for patients to keep MSM and CAM complementary.

There are several limitations in the current study. First, the definition of CAM and specific therapies used by the MEPS may differ from the ones used by other studies. Second, the MEPS data collected information on only CAM provider visits. Home or over-the-counter use of some CAM, e.g., herbs, was not included. It is very likely that the prevalence of the use of these types of CAM is higher, particularly in the Asian and Hispanic subpopulations in which herbal and home remedy use is highly prevalent (Keegan 1996; Ma 1999). We would also expect to reveal more racial and ethnic differences in the use of some CAM types had home use of CAM been included in the data, leading to an increased prevalence and a larger number of users. Another possible bias source is that not all patients can distinguish CAM providers, for example, chiropractors, from mainstream medical providers. Third, caution must be exercised when one attempts to compare the prevalence rates of CAM use derived from the current study and those from previous studies. As discussed, differences in many factors, such as study design, representation of the minority populations, content/definition of CAM, and statistical methods, are likely to lead to different estimates from various studies. Fourth, in addition to variations across different racial and ethnic groups, intragroup variations may well exist, especially in the CAM use patterns between younger and older generations. Previous studies suggested that older persons in minority groups may be more likely to use CAM than their younger counterparts (Higginbotham, Trevino, and Ray 1990; Cushman et al. 1999; Najm et al. 2003). Lastly, the pooling of data from 2 years may have masked the trend of CAM. However, in the preliminary analyses, the utilization patterns of 1996 and 1998 were very similar. No indications of significant time trends of CAM use were found.

In summary, different racial and ethnic groups may have different degrees of predisposition toward CAM use. The current study identified racial and ethnic differences in both pattern and prevalence in the use of CAM. It was found that the complementarity and substitution of CAM and MSM 
varied by racial and ethnic groups and by types of CAM. Culturally sensitive approaches are needed to successfully integrate CAM and MSM in treatment management and to avoid adverse medical/drug events due to the lack of understanding of racial and ethnic differences in CAM use in conjunction with MSM.

\section{REFERENCES}

AHRQ. Available at http://www.meps.ahrq.gov/Pubdoc/H12CB.PDF

AHRQ. Available at http://www.meps.ahrq.gov/Pubdoc/HC028/H28CB.pdf

Andersen, R., and J. F. Newman. 1973. "Societal and Individual Determinants of Medical Care Utilization in the United States." Milbank Memorial Fund Quarterly Health Society 51 (1): 95-124.

Astin, J. A. 1998. "Why Patients Use Alternative Medicine: Results of a National Study." Journal of the American Medical Asssociation 279 (19): 1548-53.

Bair, Y. A., E. B. Gold, G. A. Greendale, B. Sternfeld, S. R. Alder, R. Azari, and M. Harkey. 2002. "Ethnic Differences in Use of Complementary and Alternative Medicine at Midlife: Longitudinal Results from SWAN Participants." American Journal of Public Health 92 (11): 1832-40.

Baldwin, C. M., K. Long, K. Kroesen, A. J. Brooks, and I. R. Bell. 2002. "A Profile of Military Veterans in the Southwestern United States Who Use Complementary and Alternative Medicine: Implications for Integrated Care." Archives of Internal Medicine 162 (15): 1697-704.

Bausell, R. B., W. L. Lee, and B. M. Berman. 2001. "Demographic and Health-Related Correlates to Visits to Complementary and Alternative Medical Providers." Medical Care 39 (2): 190-6.

Burge, F., B. Lawson, and G.Johnston. 2003. "Family Physician Continuity of Care and Emergency Department Use in End-of-Life Cancer Care." Medical Care 41 (8): 992-1001.

Cherniack, E. P., R. S. Senzel, and C. X. Pan. 2001. "Correlates of Use of Alternative Medicine by the Elderly in an Urban Population." Journal of Alternative and Complementary Medicine 7 (3): 277-80.

Cohen, J. 1997 "Design and Methods of the Medical Expenditure Panel Survey Household Component." MEPS Methodology Report No. 1, AHCPR Publication No. 97-0026.

Cushman, L. F., C. Wade, P. Factor-Litvak, F. Kronenberg, and L. Firester. 1999. "Use of Complementary and Alternative Medicine among African-American and Hispanic Women in New York City: A Pilot Study.” Journal of the American Medical Womens Association 54 (4): 193-5.

Davis, M. P., and P. M. Darden. 2003. "Use of Complementary and Alternative Medicine by Children in the United States." Archives of Pediatrics Adolescence Medicine 157 (4): 393-6.

Druss, B. G., and R. A. Rosenheck. 1999. "Association between Use of Unconventional Therapies and Conventional Medical Services." Journal of the American Medical Asssociation 282 (7): 651-6. 
Egede, L. E., X. Ye, D. Zheng, and M. D. Silverstein. 2002. "The Prevalence and Pattern of Complementary and Alternative Medicine Use in Individuals with Diabetes." Diabetes Care 25 (2): 324-9.

Eisenberg, D. M., R. B. Davis, S. L. Ettner, et al. 1998. "Trends in Alternative Medicine Use in the United States, 1990-1997: Results of a Follow-up National Survey." Journal of the American Medical Asssociation 280 (18): 1569-75.

Eisenberg, D. M., R. C. Kessler, C. Foster, F. E. Norlock, D. R. Calkins, and T. L. Delbanco. 1993. "Unconventional Medicine in the United States. Prevalence, Costs, and Patterns of Use." New England Journal of Medicine 328 (4): 246-52.

Elder, N. C., A. Gillcrist, and R. Minz. 1997. "Use of Alternative Health Care by Family Practice Patients." Archives of Family Medicine 6 (2): 181-4.

Farrell, S., W. G. Manning, and M. D. Finch. 2003. "Alcohol Dependence and the Price of Alcoholic Beverages.” Journal of Health Economy 22 (1): 117-47.

Gerdtham, U. G., M. Johannesson, L. Lundberg, and D. Isacson. 1999. "A Note on Validating Wagstaff and van Doorslaer's Health Measure in the Analysis of Inequalities in Health." Journal of Health Economy 18 (1): 117-24.

Gundling, K. E. 1998. "When Did I Become an 'Allopath'?” Archives of Internal Medicine 158 (20): 2185-6.

Hakkinen, U. 2002. "Change in Determinants of Use of Physician Services in Finland between 1987 and 1996." Social Science and Medicine 55 (9): 1523-37.

Higginbotham, J. C., F. M. Trevino, and L. A. Ray. 1990. "Utilization of Curanderos by Mexican Americans: Prevalence and Predictors. Findings from HHANES 1982-84." American Journal of Public Health 80 (Supp 1): 32-5.

Humphries, K. H., and E. van Doorslaer. 2000. "Income-Related Health Inequality in Canada." Social Science and Medicine 50 (5): 663-71.

Joyce, G. F., K. Kapur, K. A. Van Vorst, and J. J. Escarce. 2000. "Visits to Primary Care Physicians and to Specialists under Gatekeeper and Point-of-Service Arrangements." American Journal of Management Care 6 (11): 1189-96.

Kahn, R. S., P. H. Wise, B. P. Kennedy, and I. Kawachi. 2000. "State Income Inequality, Household Income, and Maternal Mental and Physical Health: Cross Sectional National Survey.” British Medical Journal 321 (7272): 1311-5.

Kakwani, N., A. Wagstaff, and E. van Doorslaer. 1997. "Socioeconomic Inequalities in Health: Measurement, Computation, and Statistical Inference." Journal of Econometrics 77: 87-103.

Keegan, L. 1996. "Use of Alternative Therapies among Mexican Americans in the Texas Rio Grande Valley." Journal of Holistic Nursing 14 (4): 277-94.

Kennedy, B. P., I. Kawachi, R. Glass, and D. Prothrow-Stith. 1998. "Income Distribution, Socioeconomic Status, and Self Rated Health in the United States: Multilevel Analysis.” British Medical Journal 317 (7163): 917-21.

Kilpatrick, S.J., Jr. 1977. “Consultation Frequencies in General Practice.” Health Service Research 12 (3): 284-98.

Kim, C., and Y. S. Kwok. 1998. "Navajo use of Native Healers." Archives of Internal Medicine 158 (20): 2245-9. 
Kunst, A. E., J. J. Geurts, and J. van den Berg. 1995. "International Variation in Socioeconomic Inequalities in Self Reported Health." Journal of Epidemiology and Community Health 49 (2): 117-23.

Lillard, L. A., J. Rogowski, and R. Kington. 1999. "Insurance Coverage for Prescription Drugs: Effects on Use and Expenditures in the Medicare Population." Medical Care 37 (9): 926-36.

Liu, E. H., L. M. Turner, S. X. Lin, L. Klaus, L. Y. Choi, J. Whitworth, W. Ting, and M. C. Oz. 2000. "Use of Alternative Medicine by Patients Undergoing Cardiac Surgery." Journal of Thoracic Cardiovascular Surgery 120 (2): 335-41.

Ma, G. X. 1999. "Between Two Worlds: The Use of Traditional and Western Health Services by Chinese Immigrants.” Journal of Community Health 24 (6): 421-37.

Mackenzie, E. R., L. Taylor, B. S. Bloom, D. J. Hufford, and J. C. Johnson. 2003. "Ethnic Minority Use of Complementary and Alternative Medicine (CAM): A National Probability Survey of CAM Utilizers." Alternative Therapies in Health and Medicine 9 (4): 50-6.

McCurdy, E. A., J. G. Spangler, M. M. Wofford, A. R. Chauvenet, and T. W. McLean. 2003. "Religiosity Is Associated with the Use of Complementary Medical Therapies by Pediatric Oncology patients." Journal of Pediatrics Hematology Oncology 25 (2): 125-9.

Mullahy, J. 1998. "Much Ado About Two: Reconsidering Retransformation and the Two-Part Model in Health Econometrics." Journal of Health Economy 17 (3): 24781.

Najm, W., S. Reinsch, F. Hoehler, and J. Tobis. 2003. "Use of Complementary and Alternative Medicine among the Ethnic Elderly." Alternative Therapies in Health and Medicine 9 (3): 50-7.

Ni, H., C. Simile, and A. M. Hardy. 2002. "Utilization of Complementary and Alternative Medicine by United States Adults: Results from the 1999 National Health Interview Survey.” Medical Care 40 (4): 353-8.

Palinkas, L. A., and M. L. Kabongo. 2000. "The Use of Complementary and Alternative Medicine by Primary Care Patients. A SURF*NET Study." Journal of Family Practice 49 (12): 1121-30.

Paramore, L. C. 1997. "Use of Alternative Therapies: Estimates from the 1994 Robert Wood Johnson Foundation National Access to Care Survey." Journal of Pain Symptom Management 13 (2): 83-9.

Schellhorn, M., A. E. Stuck, C. E. Minder, and J. C. Beck. 2000. "Health Services Utilization of Elderly Swiss: Evidence from Panel Data." Health Economy 9 (6): 533-45.

Sharma, V., S. D. Simon, J. M. Bakewell, E. F. Ellerbeck, M. H. Fox, and D. D. Wallace. 2000. "Factors Influencing Infant Visits to Emergency Departments." Pediatrics 106 (5): 1031-9.

Shumay, D. M., G. Maskarinec, C. C. Gotay, E. M. Heiby, and H. Kakai. 2002. "Determinants of the Degree of Complementary and Alternative Medicine Use among Patients with Cancer." Journal of Alternative and Complementary Medicine 8 (5): 661-71. 
Soobader, M. J., and F. B. LeClere. 1999. "Aggregation and the Measurement of Income Inequality: Effects on Morbidity." Social Science and Medicine 48 (6): 733-44.

Spigelblatt, L., G. Laine-Ammara, I. B. Pless, and A. Guyver. 1994. "The Use of Alternative Medicine by Children.” Pediatrics 94 (6 part 1): 811-4.

Subramania, S. V., I. Kawachi, and B. P. Kennedy. 2001. "Does the State You Live in Make a Difference? Multilevel Analysis of Self-Rated Health in the US.” Social Science and Medicine 53 (1): 9-19.

U.S. Census Bureau. [accessed November 22, 2003]. Available at http://eire.census. gov/popest/archives/national/nation3/intfile3-1.txt

van Doorslaer, E., A. Wagstaff, H. Bleichrodt, S. Calonge, U. G. Geratham, M. Gerfin, J. Geurts, L. Gross, U. Hakkinen, R. E. Leu, O. O'Donnell, C. Propper, F. Puffer, M. Rodriguez, G. Sundberg, and O. Winkelhake. 1997. "IncomeRelated Inequalities in Health: Some International Comparisons." Journal of Health Economy 16 (1): 93-112.

Wagstaff, A., and E. Van Doorslaer. 1994. "Measuring Inequalities in Health in the Presence of Multiple-Category Morbidity Indicators.” Health Economy 3 (4): 281-9.

Watts, C. A., R. M. Scheffler, and N. P. Jewell. 1986. "Demand for Outpatient Mental Health Services in a Heavily Insured Population: The Case of the Blue Cross and Blue Shield Association's Federal Employees Health Benefits Program." Health Service Research 21 (2, part 2): 267-89. 